\title{
Article \\ Perception of and Motivation for Physical Activity among Women with a History of Gestational Diabetes
}

\author{
Julie Breinholm Svarrer Jakobsen ${ }^{1, *}$, Josefine Stæhr Brodersen ${ }^{1, *}$, Zainab Afshan Sheikh ${ }^{1}$ and \\ Karoline Kragelund Nielsen ${ }^{2}$ (D) \\ 1 Department of Public Health, University of Copenhagen, Oester Farimagsgade 5, \\ 1014 Copenhagen K, Denmark; zash@sund.ku.dk \\ 2 Health Promotion Research, Steno Diabetes Center Copenhagen, Niels Steensens Vej 6, \\ 2820 Gentofte, Denmark; karoline.kragelund.nielsen@regionh.dk \\ * Correspondence: julie_jakobsen@hotmail.com (J.B.S.J.); josefine@brodersen.nu (J.S.B.); \\ Tel.: +45-22345499 (J.B.S.J.); +45-28588096 (J.S.B.)
}

Citation: Jakobsen, J.B.S.; Brodersen, J.S.; Sheikh, Z.A.; Nielsen, K.K. Perception of and Motivation for Physical Activity among Women with a History of Gestational Diabetes. Women 2021, 1, 109-119. https://doi.org/10.3390/women 1020010

Academic Editor: Mary V. Seeman

Received: 17 April 2021

Accepted: 31 May 2021

Published: 2 June 2021

Publisher's Note: MDPI stays neutral with regard to jurisdictional claims in published maps and institutional affiliations.

\begin{abstract}
Background: Women with a history of gestational diabetes mellitus (GDM) have a high risk of developing type 2 diabetes (T2DM). This risk can be reduced with lifestyle interventions, including physical activity. However, studies have shown that many women with prior GDM are not physically active. The aim of this study was to investigate the motivation for physical activity among women with prior GDM. (2) Methods: A qualitative study was carried out based on a phenomenological approach using semi-structured individual interviews with nine Danish women between 29 and 36 years of age with a minimum of one earlier GDM-affected pregnancy. (3) Results: Five themes were identified; perception of physical activity, risk perception, emotional distress, competing priorities and social support. The perception of physical activity varied among the women. The GDM diagnosis or the awareness of elevated risk for T2DM did not seem to be a decisive factor for the women's motivation to be active. Competing priorities, including being in control of everyday life choices and support from social relations, were found to be important motivational factors. (4) Conclusion: Future interventions for women with prior GDM to increase motivation for physical activity should be compatible with and take into account the women's perceptions, earlier lived experiences, possible competing priorities and support systems.
\end{abstract}

Keywords: gestational diabetes; physical activity; perceptions; motivation; qualitative research; self-determination theory; Denmark

\section{Introduction}

Gestational diabetes mellitus (GDM) is defined as diabetes diagnosed in the second or third trimester of pregnancy that is not clearly overt diabetes prior to gestation [1]. In Denmark GDM affects 2-3\% of all pregnancies [2,3]. GDM is a transient condition, which means that blood sugar levels usually return to a normal range after childbirth. However, GDM is associated with a range of short- and long-term adverse health outcomes for both mother and child [4]. Women with former GDM have a significantly increased risk of developing type 2 diabetes mellitus (T2DM) later in life [5,6], as well as recurrent GDM in subsequent pregnancies [7].

It is well known that physical activity has a health-promoting and disease-preventing effect [8]. Research has shown that the incidence of T2DM in women with prior GDM can be significantly reduced through interventions that focus on diet, weight loss and exercise [9]. However, most women are not physically active during pregnancy and many who exercise before pregnancy decrease their activity level during and after pregnancy [10]. An observational study by Stage and colleagues showed that more than one-third of women diagnosed with GDM did not exercise either before or after their pregnancy. Neither did the proportion of women exercising increase after pregnancy [11]. Previous studies have 
highlighted a number of barriers to following a healthy lifestyle after delivery [11-14]. Willingness to engage in preventive behaviours may be influenced by the perceived threat of T2DM, and barriers and motivators to making lifestyle changes [15]. Findings from qualitative studies suggest that risk perception may be a motivating factor for physical activity among women with prior GDM $[15,16]$.

Current interventions for women with previous GDM have largely been unable to sustainably change the women's physical activity behaviour [17]. Studies show that motivation plays a critical role in women's physical activity levels $[13,16,18]$. However, there is a lack of studies investigating how women's lived experiences with GDM and their perception of a healthy lifestyle may affect their motivation to be physically active. Thus, insights are needed to understand the possible explanations as to why so few women are physically active after a GDM diagnosis. This paper aims to investigate the motivation for physical activity among women with prior GDM. Specifically, we seek to obtain a deeper understanding of the women's perception of their GDM diagnosis and their perception of what constitutes a healthy lifestyle, and how these perceptions may affect their motivation for physical activity. We apply a phenomenological approach to discover the women's articulations and thereby understanding of physical activity, and not the actual activity level in the form of actions.

The goal of the phenomenological approach is to capture the human experience as it manifests itself in a specific lifeworld. Through phenomenology, we aim to include and present the women's particular perceptions. This refers to subjective experiences of each individual, which affects how various phenomena are experienced [19]. It makes it possible to investigate whether the GDM diagnosis affects the women's lived experiences and priorities as well as relationships to others. With this approach we place ourselves within a subjective ontology. Using a qualitative method we recognize the idea of multiple perceptions of reality [20]. Therefore, we are not investigating the possible coupling or friction between their articulations and actions or questioning their perception of physical activity. Instead, this paper will rely on the women's voices and lived experiences.

We believe that the understanding of the motivation for physical activity is a key insight to understand the gap in prevention of T2DM. We hope to provide information to support approaches that engage women affected by GDM in taking steps to reduce their risk for T2DM.

\section{Materials and Methods}

\subsection{Study Design}

In this study we used qualitative research methodologies guided by a phenomenological approach supported by Deci \& Ryan's Self Determination Theory [20-22]. The phenomenological approach involves in-depth examinations of not only the participants' lived experiences but also their perceptions, all expressed in their own words [23]. Thus, this approach makes it possible to gain detailed insights and nuances into the women's motivation for physical activity. As researchers, we aim to share the women's point of view. Within the social constructivist way of thinking one tries to avoid validating one certain truth. Instead the aim is to come up with possible (new) explanations and ways of viewing the prevailing knowledge in the field [20].

The inclusion of Self Determination Theory made it possible to analyse the interview statements and perception of physical activity by explaining the relation between autonomy, competence and motivation [24]. The focus of the study is on motivation and perception, and not determination of the actual activity level. All information about the women, their partners, and children are fictive (names, housing etc.).

\subsection{Recruitment}

Seven participants were recruited through social media platforms, and two through a personal contact, which resulted in nine semi-structured interviews. The concept of theoretical saturation was followed and met, i.e., recruitment continued until encountering 
a series of repetitions across interviews and no new findings occurred [25]. No new themes were presented by the women during the last three interviews and recruitment was therefore ended.

Participants were recruited purposively using a non-random selection strategy, and they were not restricted to a particular BMI. This was aimed at getting different background and geographic characteristics represented among the participants. Thus, through a heterogeneous selection process within the target group, maximum variation was sought. This is beneficial to illustrate variation as well as common patterns within a phenomenon [25]. All nine women represented a different profile within geography, parity, variation in time after GDM and number of GDM cases (see Table 1). Six women declined to participate due to lack of time, illness or unknown reasons.

Table 1. Characteristics of study participants.

\begin{tabular}{|c|c|c|c|c|c|c|}
\hline $\begin{array}{l}\text { Participant's } \\
\text { Pseudonyms }\end{array}$ & Age & $\begin{array}{c}\text { Place of } \\
\text { Residence }\end{array}$ & Marital Status & Education & Occupation & $\begin{array}{c}\text { Time since } \\
\text { GDM * }\end{array}$ \\
\hline Woman 1 & 32 & $\begin{array}{l}\text { Copenhagen } \\
\text { Area }\end{array}$ & $\begin{array}{l}\text { Married and } \\
\text { cohabiting }\end{array}$ & $\begin{array}{l}\text { Higher education } \\
\text { (postgraduate degree) } \\
\text { Long cycle higher } \\
\text { education }\end{array}$ & $\begin{array}{l}\text { Unemployed } \\
\text { (currently on } \\
\text { maternity leave) }\end{array}$ & 6 months \\
\hline Woman 2 & 31 & $\begin{array}{l}\text { Southern } \\
\text { Zealand }\end{array}$ & Cohabiting & $\begin{array}{l}\text { Primary and lower } \\
\text { secondary education }\end{array}$ & $\begin{array}{l}\text { Unemployed } \\
\text { (currently on } \\
\text { maternity leave) }\end{array}$ & $\begin{array}{l}8 \text { months, } \\
5 \text { years, } \\
7 \text { years, } \\
12 \text { years }\end{array}$ \\
\hline Woman 3 & 36 & $\begin{array}{c}\text { Copenhagen } \\
\text { Area }\end{array}$ & $\begin{array}{l}\text { Married and } \\
\text { cohabiting }\end{array}$ & $\begin{array}{l}\text { Upper secondary } \\
\text { education }\end{array}$ & Unemployed & $\begin{array}{l}2 \text { years, } \\
4 \text { years }\end{array}$ \\
\hline Woman 4 & 29 & $\begin{array}{l}\text { Southwest } \\
\text { Jutland }\end{array}$ & $\begin{array}{l}\text { Married and } \\
\text { cohabiting }\end{array}$ & $\begin{array}{l}\text { Upper secondary } \\
\text { education }\end{array}$ & Working & 1.5 years \\
\hline Woman 5 & 29 & $\begin{array}{l}\text { Southern } \\
\text { Jutland }\end{array}$ & Cohabiting & $\begin{array}{l}\text { Upper secondary } \\
\text { education }\end{array}$ & $\begin{array}{l}\text { Working (currently } \\
\text { on maternity leave) }\end{array}$ & $\begin{array}{l}6 \text { months, } \\
2 \text { years, }\end{array}$ \\
\hline Woman 6 & 36 & Funen & Cohabiting & $\begin{array}{c}\text { Higher education } \\
\text { (postgraduate degree) }\end{array}$ & Working & $\begin{array}{l}2.5 \text { years, } \\
7 \text { years, } \\
9 \text { years }\end{array}$ \\
\hline Woman 7 & 30 & $\begin{array}{l}\text { Copenhagen } \\
\text { Area }\end{array}$ & $\begin{array}{l}\text { Divorced and } \\
\text { living alone }\end{array}$ & $\begin{array}{l}\text { Vocational education } \\
\text { and training }\end{array}$ & Working & 8 months \\
\hline Woman 8 & 33 & $\begin{array}{l}\text { Northern } \\
\text { Jutland }\end{array}$ & Cohabiting & $\begin{array}{l}\text { Vocational education } \\
\text { and training }\end{array}$ & $\begin{array}{l}\text { Working (currently } \\
\text { on maternity leave) }\end{array}$ & 7 months \\
\hline Woman 9 & 32 & $\begin{array}{l}\text { Northern } \\
\text { Jutland }\end{array}$ & $\begin{array}{l}\text { Married and } \\
\text { cohabiting }\end{array}$ & $\begin{array}{l}\text { Primary and lower } \\
\text { secondary education } \\
\text { (ongoing) }\end{array}$ & Studying & 2.5 years \\
\hline
\end{tabular}

* Each time mentioned refers to one pregnancy with GDM. Women 2, 3, 5 \& 6 had multiple GDM pregnancies.

The locations for the interviews were decided by the participants. This resulted in five interviews taking place in the informant's home, one at a library, one in a health care centre and the remaining two via Skype. The interviews were conducted by JSB and JBSJ.

\subsection{Interview Guide}

A semi-structured interview guide with mainly open-ended questions was used in the interviews. The guide used abductive reasoning, which differs from inductive or deductive reasoning by its focus on context. We started with an incomplete set of observations before moving towards likely explanations. This involved inclusion of the researcher's pre-understanding of the target group, of the topic and of existing theory [26]. Respecting the essential concept of getting more familiar with the topic throughout the process [19], the interview guide was flexible and adaptable to the topics and themes brought up by the 
women. This created room for new topics, including the women's different perceptions of physical activity and emotional distress, to be further explored. This is consistent with the phenomenological approach where the pre-understanding is included throughout the process of the study [27]. Phenomenology focuses on structures of consciousness as experienced from the first-person point of view. Applying a phenomenological approach foregrounds the experience of everyday life from the perspective of each individual [28].

The questions were framed with a focus on achieving a dynamic conversation facilitating the ability to speak freely [29]. The first initial interview resulted in rephrasing, removal and merging of several questions. This interview provided useful insights into the topic and was therefore included in the final analysis. The final interview guide consisted of questions focusing on personal experiences related to the women's everyday life (including physical activity and the GDM diagnosis). Each interview lasted between 45 and 90 min.

\subsection{Thematic Analysis}

All interviews were audio recorded and verbatim transcribed by JSB and JBSJ shortly after they took place, to maintain as many details as possible from the women's statements. Hereafter followed an analysis consisting of four steps:

1. JSB and JBSJ individually searched for repetitive trends in the data using field notes made during the interviews and multiple read-throughs of the transcripts. These trends were compared, discussed, and condensed into five overall themes.

2. JSB and JBSJ identified meaning units by employing systematic open coding of text fragments using NVIVO 10 (QSR International Pty Ltd., Doncaster, Australia) to assist the organisation of codes (see Table 2).

3. JSB and JBSJ operationalized the final themes and reconsidered the structure through examination of repetitions and overlaps, followed by rearranging and erasing until the final themes were formed.

4. Finally, a recontextualization of the data. Here, the statements were analysed using Self Determination Theory by Deci \& Ryan [20] to develop structures and explore meanings [30].

Table 2. Example of meaning units and their associated category and theme.

\begin{tabular}{ccc}
\hline Meanings Unit & Condensed Meaning Unit & Theme \\
\hline "When you have three children. Going for a run is & & \\
something you need your partner to support... that it & Importance of social support (more or & Experience of social support \\
is okay to go for a run. [that he says] 'I will look out & less physically active) & \\
for the kids'. But I often experience the opposite." & & \\
(Woman 6) & & \\
\hline
\end{tabular}

\subsection{Ethical Approval}

According to Danish legislation, studies employing qualitative methodologies are exempt from requiring ethical approval. The authors' received confirmation of this from the Danish Regional Ethical Committee and the National Science Ethics Committee.

Written and oral informed consent was obtained from all participants prior to the interviews, giving us access to the women's thoughts and reflections, opinions, life stories, experiences, and concerns. The women received an invitation in Danish informing them that the interview would concern the role of their GDM diagnosis and the role of physical activity in their daily lives. The women were assured that all information would be treated confidentially and that their words, when published, would be anonymous. When entering the interviews, the women informed us about their age, height, weight, marital status, parity, time since given birth and GDM diagnosis, level of education and employment. Through the consent we made sure that all participants understood the use of the personal information shared, and that participation was voluntary with the opportunity to withdraw at any time. 


\section{Results}

\subsection{Participants}

Interviews took place with the nine women, diagnosed with GDM between six months and three years prior to the interview. The women's ages during the interviews ranged from 29 to 36 years. Approximately half of the women were married, on maternity leave and had more than one GDM affected pregnancy at the time of interview. Further, there was a broad representation in terms of educational background. An overview of the specific characteristics of the women can be found in Table 1.

\subsection{Themes}

Five interrelated themes emerged from the data related to the women's motivation for physical activity. These were (1) perception of physical activity, (2) risk perception, (3) emotional distress, (4) competing priorities and (5) social support. In the following, all themes are summarised and substantiated through quotes from the interviews. Combined, the themes provide an insight into how the women's motivation for physical activity is shaped by both perception of a healthy lifestyle and lived experiences. Especially, theme 1 and 2 provide an insight into the women's perceptions of a healthy lifestyle, through their views on daily priorities and health risks. Internal factors, presented through themes 1-3, and external factors, which themes $4-5$ present, contribute to the possible construction of motivation for physical activity.

\subsubsection{Theme 1: Perception of Physical Activity}

The women's motivation to be physically active was connected to their perception of physical activity, which was affected by their lived experiences with GDM. The women described dissimilar understandings and perceptions of physical activity. Some women considered physical activity to be movement in connection with daily transport, walking the dog, gardening, cleaning, doing dishes, washing clothes, playing with children etc. These women described themselves as being physically active through household activities, also in connection with time spent at home during maternity leave. Woman 8 explained how she considered herself being physically active doing these kinds of activities in an otherwise busy day while on maternity leave: "...now I walk a lot with the baby carriage... and I also see it as physical activity if I am doing gardening" (Woman 8). Her perception of physical activity was thus formed by her situation and possibilities in a busy everyday life. Other women described physical activity as more conscious, goal-oriented and with regular "workouts", with the direct intention towards obtaining (or maintaining) better health and well-being; this involved sweating, higher intensity and high pulse. The women categorising physical activity as "work-outs" instead of "daily movement" had experience and success in prioritising specific time frames for physical activity, such as woman $3:$ " I probably define it [physical activity] more as something where I set time aside and get sweaty before I see it as physical activity - as opposed to just walking the dog" (Woman 3).

Overall, we found that when physical activity was perceived as an actively chosen positive addition to their preferred way of living their everyday lives, the women experienced an increased motivation. For the women, who were able to prioritise physical activity in their lives, a key motivational factor was being in control of everyday activities and priorities by choosing not only when but also how to be physically active. Woman 6-a full-time working mother of three children-explained how physical activity is a fundamental part of her life: "I use it to get a break, to get power and energy for my other tasks at home /... / You know ... It is just an hour where I am in the zone-totally disconnected, away from work. I just swim" (Woman 6). This woman referred to earlier positive experiences and associated physical activity with surplus energy and a way to prioritise her own needs. The findings suggest that the women's perception of physical activity frames their motivation to be active. 


\subsubsection{Theme 2: Risk Perception}

Most of the women expressed awareness of their elevated risk of T2DM due to the GDM diagnosis. However, only few of the women mentioned physical activity in particular as a means to lower their risk of future T2DM. Only one woman expressed being motivated to be physically active due to her fear of future T2DM: "I guess it is because GDM has created a fear of getting type 2 diabetes because there is a connection to the lifestyle. After GDM I am going [to the gym]. I think it is a feeling of "now I did something good to minimise that risk"" (Woman 3).

Some women described how the fear of the baby's risk of developing future health problems (e.g., T2DM) was the main reason they paid special attention to their lifestyle during their pregnancy. For the same reason they felt more motivated to be physically active. But after giving birth this motivation changed because their lifestyle was perceived to no longer affect their children directly: "After all, now it will only affect me, and not my baby anymore. So, then I've probably slacked on the physical activity after I have given birth [laughs]. But you still have it in mind, because I am very aware that the risk for developing diabetes is higher" (Woman 5). One woman explained how the GDM diagnosis changed her perception of physical activity, but instead of changing her own motivation to be physically active it motivated her to make her son's life more active: "I think it is pretty important that it [physical activity] is a part of my son's childhood. Particularly because of his elevated risk of T2DM" (Woman 1). Woman 1 thus drew a direct parallel between behaviour and risk when it came to her son, but regarding her own actions she did not mention being motivated to be more physically active despite her knowledge of the connection between physical activity and future risk of T2DM.

\subsubsection{Theme 3: Emotional Distress}

Several women had experienced emotional distress due to the GDM diagnosis, which appeared to be a potential barrier for physical activity. The women expressed how the diagnosis had negative psychological implications, such as worrying and trying to make sense of it. This was present both during and after the GDM-affected pregnancy and removed the focus from their own future health. Woman 5 explained feelings of guilt, shame and responsibility: "When I got the diagnosis I thought, 'Oh no, is it because I have been eating what I shouldn't or haven't been moving enough?'. There must be reasons why you are overweight. So, I can't help but blame myself a bit because you don't get fat just like that" (Woman 5). The findings suggest that instead of the GDM diagnosis motivating the women to be physically active, it resulted in more time spent on blaming themselves and having negative thoughts where physical activity became less of a priority. Other obstacles expressed by the women were competing priorities in a busy everyday life with small children, as described in the following.

\subsubsection{Theme 4: Competing Priorities}

An important theme that emerged through the interviews was that of competing priorities to physical activity, such as other health risks, time spent with children, duties as a mother etc. The experience of having competing priorities (and limited time) in their everyday lives formed how the women related and felt motivated to be physically active. Thus, while many of the women expressed the wish to be more physically active, they also described that other activities in their everyday lives had higher priority. Woman 5 used to be physically active before she had her two children. She explained: "The priority of exercise has been different after having children /.../ even when you really want it, there are many other things to arrange, which makes it challenging to also exercise" (Woman 5). Like Woman 5, most of the women explained that their priorities changed after having children, which challenged their available resources. This was both mentioned in terms of time, which all women mentioned as an important factor in their motivation for physical activity, but also money (e.g., paying for a gym membership). Another important aspect of this included actions related to being considered a good mother. Several of the women mentioned that time spent on physical activity created less time for the children. Woman 7-a single 
mother working full time-emphasised that her worries about other co-occurring serious health problems made no room to think about preventing T2DM through physical activity. When talking about physical activity to improve her life after GDM she explained that the condition was not life threatening and therefore she was not motivated to prioritise it.

\subsubsection{Theme 5: Social Support}

The motivational factors, barriers and competing priorities described in the previous themes were all influenced by the presence of social support. Thus, all women highlighted the experience of social support from partners, family, and friends as a key motivational factor to be physically active. Especially, support from the partner was described as crucial. This support created motivation for physical activity due to more time and opportunities, as explained by woman 1 who had recently given birth to her first child. She explained how she was struggling to create good routines during her maternity leave: "I feel that my husband always supports me to be active /.../ he is trying to make time, so we make sure that I at least go and attend the yoga classes" (Woman 1). Other women explained how a lack of support often became the reason why they were not motivated to be physically active. One woman explained: "When you have three children. Going for a run is something you need your partner to support... that it is okay to go for a run, [that he says] 'I will look out for the kids'. But I often experience the opposite" (Woman 6). These examples state the importance of both practical and emotional support to create motivation for the women to be physically active.

\section{Discussion}

This qualitative study investigated the motivation for physical activity among women with a prior GDM diagnosis and identified five themes of interest: perception of physical activity, risk perception, emotional distress, competing priorities and social support. By focusing on the women's motivation to be physically active, and not whether they are actually being active, a possible link between motivation and actions was not the aim of this study. Instead, these themes give a valuable insight into possible facilitators and barriers for the women to live an active life, which can benefit future studies and interventions. We have analysed data through the women's articulations and presented lived experiences.

Our findings suggest that the women's perceptions of physical activity are individual, and often affected by earlier experiences with physical activity. Some of the women did not recognise actions, such as walking the dog, as "proper" physical activity. This may create an additional pressure with a possible negative influence on their motivation. This finding is important for health practitioners to have in mind, when it comes to the ambition to increase the women's activity level. Health promotion among these women ought to be tailored to the individual person. Further, there should be a focus on encouragement of any type of physical activity rather than to blame women for not being physically active in a specific way.

Deci and Ryan's Self-Determination Theory supports our findings. According to their theory, self-management and autonomy are crucial factors for motivation, where different types of motivation control everyday choices and behaviour. In our study, the women seek to be in control over when and how they are physically active. It is an important insight that the women's motivation only arises when they can choose the preferred and suitable type of activity on their own.

Several studies have found that women diagnosed with GDM are unaware of their increased risk of T2DM [18,20-22]. In contrast, the women in our study were aware of the increased risk of T2DM, and especially women with a high education level expressed a high level of awareness of the risk of T2DM after a GDM diagnosis. However, this risk awareness did not seem to be translated into an increased motivation for physical activity to prevent future T2DM. Only one of the women described being motivated to change her current activity level due to the GDM diagnosis and her fear of future T2DM.

Furthermore, we found that emotional distress among the women due to the GDM diagnosis possibly resulted in self-blame and guilt, which minimised their motivation to 
be physically active. A focus on the risk of getting a disease in future interventions may cause further emotional distress, lead to medicalization and foster negative emotions such as shame, guilt and feelings of being an insufficient mother. This is important to have in mind for health professionals and interventions planners, to make sure that they focus on positive implications for motivation instead of increased knowledge of risk.

Our study suggests-in the perception of the women - that the GDM diagnosis plays a minor role in motivating them to be physically active. Instead, the women's motivation seems affected by other health problems, or simply by other duties and obligations associated with being a good mother, which they find more important. Lack of resources, especially time, in their busy everyday life requires substantial prioritisation. In line with findings from other studies $[18,23]$ the women in our study reported downgrading physical activity as they set the needs of the family before their own. Motivation to spend more time with their children prevailed upon the motivation to spend time on physical activity. Several of the women had the belief that physical activity required more than e.g., walking the dog or walking with the baby carriage. A broader understanding could have served as a motivational factor for the women to be more physically active while taking care of their children.

The women also highlight social support as a crucial motivational factor. Deci and Ryan describe that social relations and support can be of greater importance than the ability to self-motivate $[24,25]$. Autonomy and intrinsic motivation are key for long term physical activity participation. Though it is only when the women have met their needs for autonomy and competence as well as social affiliation in decision making that the motivation will increase and lead to actual behaviour change [26,27]. Therefore, support from partner and other social relations combined with the feeling of self-control over everyday life priorities seem to be of crucial importance for the women to become more physically active.

In line with our findings, another Danish study by Svensson et al. [31] found that aspects such as time, resources and social support are important motivational factors for the women. Contrary to our study, however, Svensson et al. found that women's motivation for physical activity is guided by external factors with a low degree of autonomy [31]. We found that through a broader understanding of physical activity internal factors plays a crucial role for the women's motivation to be physically active. This includes the women's perception of physical activity, understanding of risk and level of emotional distress. Further, all the women experienced being motivated when having the autonomy to choose when and how to be active. However, when physical activity was presented as something that interferes with their perceptions and priorities, they appeared to lose their motivation for physical activity.

Our findings call for further research focusing on involvement of women with prior GDM and gaining a broader insight into their lived experiences and perception of physical activity when organising interventions. Thereby focusing on the preferred form of physical activity for the individual women and increasing internal feeling of control to create intrinsic motivation. It is crucial to include women with prior GDM in future health promotion interventions to create dialogs and ownership that can lead to motivation for action. This is not limited to a specific type of study or intervention. It is considered less paternalistic and more effective as it induces more autonomy in the target group [32]. The importance of autonomy is supported by our findings, where the women express a need for internal control. Furthermore, interventions for women following a GDM-affected pregnancy should focus on the importance of social support, especially from partners.

Health behaviours are influenced by a number of complex and contextual factors and beliefs, such as social, economic and cultural [33]. The design and implementation of possible interventions should focus on practicalities and worries connected to everyday lives among the target group. Our study provides potential target areas for women with previous GDM by gaining insight into how motivation of physical activity is affected by the women's perceptions and lived experiences. 


\section{Strengths and Limitations}

This study used a purposive sampling approach to achieve diversity of the sample within geography, parity, and variation in time after GDM, number of GDM pregnancies and socio-economic status. We used different recruitment strategies (e.g., social media and a personal contact) to reach women with different backgrounds. This gave us the opportunity to get a broad and diverse understanding of the topic and may also make the results applicable to a broader Danish context.

From the start, we expected recruitment challenges due to the women's busy lives caring for small children as well as the perceived stigma of GDM [34] and its association with obesity [35]. This can be a possible explanation why more than half of the initially approached interviewees declined after first point of contact.

We sought to investigate the perceptions and motivations for physical activity as it unfolds in everyday lives of the women by examining reported important factors knowing it might differ from what could be observed. Our analysis is based on what the women chose to share, strengthening the validity, by making their voice influence the focus on the study through continuous adjustments and openness to deviations of the interview guide. It is important to have in mind that we have focused on the women's motivation to be physically active; and not whether they are actually physically active, which could have provided interesting insights but is outside the scope and design of this study.

We are aware that motivation is a complex theme to investigate. This study serves as an initial contribution but is not able to cover this complexity fully and would benefit from further expansion and enrichment.

The phenomenological approach ensured an ongoing awareness of how our preconceptions affected our understanding of GDM during the study-process-from interviewing the women to analysing our results. This method has created a platform for the women's voice to be in the centre when focusing on what they wanted to share instead of what we expected to hear.

Finally, the phenomenological approach allowed us to provide context specific findings through a safe setting. They are shaped by the time and place of the interviews and the connection between the women and JSB and JBSJ.

\section{Conclusions}

Through a phenomenological approach this study contributes to the understanding of motivation for physical activity following a GDM-affected pregnancy. Our findings suggest that it is important to gain insight in both earlier life experiences and perceptions among the women, who had different perceptions of physical activity. The GDM diagnosis has negative consequences for the women, such as worrying and trying to make sense of the diagnosis but does not seem to serve as a decisive factor for motivation for physical activity. Furthermore, most women articulated awareness of their elevated risk of T2DM, but only few connected physical activity as a means to lower their risk, and only one woman described being motivated to be more physically active due to her fear of future T2DM. Instead of future health risks, worries and concerns in the present were a decisive factor for downgrading physical activity. Internal control over everyday life and priorities and, therefore, deciding not only when but also how they are physically active, are fundamental for the women's motivation for physical activity. Additionally, support from social relations, especially from the partner, is of key importance and can help to create more time and opportunities and thereby motivation to be physically active.

Author Contributions: Conceptualization, J.S.B., J.B.S.J., K.K.N., Z.A.S.; methodology, J.S.B., J.B.S.J., K.K.N., Z.A.S.; software, J.S.B. and J.B.S.J.; validation, J.S.B. and J.B.S.J.; formal analysis, J.S.B. and J.B.S.J.; investigation, J.S.B. and J.B.S.J.; resources, J.S.B. and J.B.S.J.; data curation, J.S.B. and J.B.S.J.; writing —original draft preparation, J.S.B. and J.B.S.J.; writing-review and editing, J.S.B., J.B.S.J., K.K.N. and Z.A.S.; visualization, J.S.B. and J.B.S.J.; supervision, Z.A.S. and K.K.N.; project administration, J.S.B. and J.B.S.J.; funding acquisition, not applicable. All authors have read and agreed to the published version of the manuscript. 
Funding: This research did not receive any specific grant from funding agencies in the public, commercial, or not-for-profit sectors.

Institutional Review Board Statement: The study was conducted according to the Danish legislation. Ethical review and approval were waived for this study, since studies employing qualitative methodologies are exempt from requiring ethical approval in Denmark. This was confirmed by the Danish Regional Ethical Committee.

Informed Consent Statement: Written and oral informed consent was obtained from all subjects involved in the study.

Data Availability Statement: Due to ethical reasons, the interview-samples are not available to the public.

Acknowledgments: We wish to thank the women who participated in the study.

Conflicts of Interest: K.K.N. is employed at Steno Diabetes Centre Copenhagen, a public hospital and research institution under the Capital Region of Denmark, which is partly funded by a grant from Novo Nordisk Foundation. J.S.B., J.B.S.J. and Z.A.S. declare no conflict of interest.

\section{References}

1. American Diabetes Association. Classification and Diagnosis of Diabetes: Standards of Medical Care in Diabetes-2019. Diabetes Care 2019, 42, 13-28.

2. Jeppesen, C.; Maindal, H.T.; Kristensen, J.K.; Ovesen, P.G.; Witte, D.R. “National study of the prevalence of gestational diabetes mellitus among Danish women from 2004 to 2012. Scand. J. Public Health 2017, 45, 811-817. [CrossRef] [PubMed]

3. Nielsen, K.K.; Andersen, G.S.; Damm, P.; Andersen, A.-M.N. Gestational Diabetes Risk in Migrants. A Nationwide, Register-Based Study of all Births in Denmark 2004 to 2015. J. Clin. Endocrinol. Metab. 2020, 105, e692-e703. [CrossRef] [PubMed]

4. Damm, P. Kliniske retningslinier for gestationel diabetes mellitus (GDM). In Screening, Diagnostik, Behandling og Kontrol Samt Follow-Up Efter Fødslen; Sundhedsstyrelsen: Copenhagen, Denmark, 2009.

5. Bellamy, L.; Casas, J.-P.; Hingorani, A.D.; Williams, D. Type 2 diabetes mellitus after gestational diabetes: A systematic review and meta-analysis. Lancet 2009, 373, 1773-1779. [CrossRef]

6. Kim, C.; Newton, K.M.; Knopp, R.H. Gestational diabetes and the incidence of type 2 diabetes: A systematic review. Diabetes Care 2002, 25, 1862-1868. [CrossRef]

7. Kim, C.; Berger, D.K.; Charmany, S. Recurrence of gestational diabetes mellitus: A systematic review. Diabetes Care 2007, 30, 1314-1319. [CrossRef]

8. WHO. Global Strategy on Diet, Physical Activity and Health. 2020. Available online: https://www.who.int/dietphysicalactivity/ $\mathrm{pa} / \mathrm{en} /$ (accessed on 10 February 2021).

9. Aroda, V.R.; Christophi, C.A.; Edelstein, S.L.; Zhang, P.; Herman, W.H.; Barrett-Connor, E.; Delahanty, L.M.; Montez, M.G.; Ackermann, R.T.; Zhuo, X.; et al. The Effect of Lifestyle Intervention and Metformin on Preventing or Delaying Diabetes Among Women with and Without Gestational Diabetes: The Diabetes Prevention Program Outcomes Study 10-Year Follow-Up. J. Clin. Endocrinol. Metab. 2015, 100, 1646-1653. [CrossRef]

10. Hegaard, H.K.; Pedersen, B.K.; Nielsen, B.B.; Damm, P. Leisure time physical activity during pregnancy and impact on gestational diabetes mellitus, pre-eclampsia, preterm delivery and birth weight: A review. Acta Obstet. Gynecol. Scand. 2007, 86, 1290-1296. [CrossRef]

11. Stage, E.; Ronneby, H.; Damm, P. Lifestyle change after gestational diabetes. Diabetes Res. Clin. Pract. 2004, 63, 67-72. [CrossRef]

12. Nielsen, K.K.; Kapur, A.; Damm, P.; de Courten, M.; Bygbjerg, I.C. From screening to postpartum follow-up-the determinants and barriers for gestational diabetes mellitus (GDM) services, a systematic review. BMC Pregnancy Childbirth 2014, $14,41$. [CrossRef]

13. Smith, B.J.; Cheung, N.W.; Bauman, A.E.; Zehle, K.; McLean, M. Postpartum Physical Activity and Related Psychosocial Factors Among Women with Recent Gestational Diabetes Mellitus. Diabetes Care 2005, 28, 2650-2654. [CrossRef]

14. Zulfiqar, T.; Lithander, F.E.; Banwell, C.; Young, R.; Boisseau, L.; Ingle, M.; Nolan, C.J. Barriers to a healthy lifestyle post gestational-diabetes: An Australian qualitative study. Women Birth 2017, 30, 319-324. [CrossRef]

15. Tang, J.W.; Foster, K.E.; Pumarino, J.; Ackermann, R.T.; Peaceman, A.M.; Cameron, K.A. Perspectives on Prevention of Type 2 Diabetes After Gestational Diabetes: A Qualitative Study of Hispanic, African-American and White Women. Matern. Child Health J. 2015, 19, 1526-1534. [CrossRef]

16. Nicklas, J.M.; Zera, C.A.; Seely, E.W.; Abdul-Rahim, Z.S.; Rudloff, N.D.; Levkoff, S.E. Identifying postpartum intervention approaches to prevent type 2 diabetes in women with a history of gestational diabetes. BMC Pregnancy Childbirth 2011, 11, 23. [CrossRef]

17. Buelo, A.K.; Kirk, A.; Lindsay, R.S.; Jepson, R.G. Exploring the effectiveness of physical activity interventions in women with previous gestational diabetes: A systematic review of quantitative and qualitative studies. Prev. Med. Rep. 2019, 14, 100877. [CrossRef] 
18. Graco, M.; Garrard, J.; Jasper, A.E. Participation in physical activity: Perceptions of women with a previous history of gestational diabetes mellitus. Heal. Promot. J. Aust. 2009, 20, 20-25. [CrossRef]

19. Kvale, S.; Brinkmann, S. Interview: Det kvalitative forskningsinterview som håndværk, 3rd ed.; Hans Reitzels: Copenhagen, Denmark, 2015; pp. 43-104.

20. Creswell, J.W. Qualitative Inquiry E Research Design, Choosing Among Five Approaches, 4th ed.; Sage Publishing: London, UK, 2017.

21. Ryan, R.M.; Deci, E.L. Self-Determination Theory: Basic Psychological Needs in Motivation, Development, and Wellness; Guilford Publications: New York, NY, USA, 2017.

22. Ryan, R.M.; Deci, E.L. Self-Determination Theory and the Facilitation of Intrinsic Motivation, Social Development, and Well-Being. Am. Psychol. 2000, 55, 68-78. [CrossRef]

23. Zahavi, D. Fænomenologi; Roskilde Universitetsforlag: Roskilde, Denmark, 2004.

24. Deci, E.L.; Ryan, R.M. Self-determination theory: A macrotheory of human motivation, development, and health. Can. Psychol. Can. 2008, 49, 182-185. [CrossRef]

25. Gentles, S.J.; Charles, C.; Ploeg, J.; McKibbon, K.A. Sampling in Qualitative Research: Insights from an Overview of the Methods Literature. CAHSS J. 2015, 20, 1772-1789.

26. Skovdal, M.; Cornish, F. Qualitative Research for Development; Practical Action Publishing Ltd.: Warwickshire, UK, 2015.

27. Brogård Kristensen, D. Fænomenologi. Filosofi, metode og analytisk værktøj. In Forskningsmetoder i Folkesundhedsvidenskab, 4th ed.; Munksgaard: København, Denmark, 2011; pp. 182-205.

28. Moran, D. The Phenomenological Approach. In The Oxford Handbook of Phenomenological Psychopathology; Stanghellini, G., Broome, M., Raballo, A., Fernandez, A.V., Fusar-Poli, P., Rosfort, R., Eds.; Oxford University Press: Hong Kong, China, 2019 ; pp. $204-215$.

29. Christensen, U.; Nielsen, A.; Schmidt, L. Det kvalitative forskningsinterview. In Forskningsmetoder i Folkesundhedsvidenskab, 4th ed.; Munksgaard: København, Denmark, 2011; pp. 61-90.

30. Dahlager, L.; Fredslund, H. Hermeneutisk analyse. In Forskningsmetoder i Folkesundhedsvidenskab, 4th ed.; Munksgaard: København, Denmark, 2011; pp. 157-182.

31. Svensson, L.; Nielsen, K.K.; Maindal, H.T. What is the postpartum experience of Danish women following gestational diabetes? A qualitative exploration. Scand. J. Caring Sci. 2018, 32, 756-764. [CrossRef]

32. Kamper-Jørgensen, F. Forebyggende Sundhedsarbejde, 4th ed.; Gyldendal Akademisk: København, Denmark, 2003.

33. Grant, J.; Mackinnon, A.; Christensen, H.; Walker, J. Participants' perceptions of motivation, randomisation and withdrawal in a randomised controlled trial of interventions for prevention of depression. J. Med. Ethics 2009, 35, 768-773. [CrossRef] [PubMed]

34. Parsons, J.; Sparrow, K.; Ismail, K.; Hunt, K.; Rogers, H.; Forbes, A. Experiences of gestational diabetes and gestational diabetes care: A focus group and interview study. BMC Pregnancy Childbirth 2018, 18, 25. [CrossRef] [PubMed]

35. Puhl, R.M.; Heuer, C.A. Obesity Stigma: Important Considerations for Public Health. Am. J. Public Health 2010, 100, 1019-1028. [CrossRef] [PubMed] 